D.O.I.: $10.3895 / \mathrm{S} 1808-04482008000100001$

\title{
COMPETÊNCIAS ORGANIZACIONAIS PARA INOVAR NA INDÚSTRIA BRASILEIRA DE IMUNOBIOLÓGICOS: UM ESTUDO DE CASO
}

\section{ORGANIZATIONAL CAPABILITIES TO INNOVATE IN THE BRAZILIAN IMNUNOBIOLOGICALS INDUSTRY: A CASE STUDY}

\author{
Antonio de Pádua Risolia Barbosa ${ }^{1}$; José Vitor Bomtempo²; Rosiceli Barreto Gonçalves \\ Baetas $^{3}$ \\ ${ }^{1}$ Fundação Oswaldo Cruz - Bio-Manguinhos - Rio de Janeiro - Brasil barbosa@bio.fiocruz.br \\ ${ }^{2}$ Universidade Federal do Rio de Janeiro - UFRJ - Rio de Janeiro - Brasil vitor@eq.ufrj.br \\ ${ }^{3}$ Fundação Oswaldo Cruz - Fiocruz - Rio de Janeiro - Brasil rosiceli@,fiocruz.br
}

\begin{abstract}
Resumo
Este trabalho apresenta uma avaliação do desenvolvimento de competências organizacionais necessárias para inovar em uma Organização que desenvolveu capacidades tecnológicas básicas através de aquisição externa de tecnologia e que busca atingir característica de inovadora. Partindo da visão de que as competências são acumuladas nas organizações em níveis crescentes de complexidade, do básico ao avançado, avalia-se a percepção dos funcionários em relação ao nível de desenvolvimento dessas competências na organização. Os resultados indicam que apesar do esforço na aquisição de tecnologias e conhecimento externo, de diversas formas, esse ainda não se traduz na conversão do conhecimento individual em conhecimento organizacional. A percepção das pessoas que trabalham no Instituto é que as competências organizacionais não relacionadas ao conhecimento ainda se encontram pouco desenvolvidas.
\end{abstract}

Palavras-chave: competências organizacionais; aprendizagem organizacional; competências para inovar.

\section{Introdução}

O mercado de vacinas para uso humano, cujas empresas são intensivas em tecnologia, apresenta características oligopolistas, com a produção, as atividades de pesquisa e o desenvolvimento tecnológico concentrados nas grandes empresas transnacionais. Elas investem no desenvolvimento de novos produtos, adotando diferentes estratégias de pesquisa e desenvolvimento (P\&D). Utilizam-se de aquisições de outras empresas, associações e estratégicas, como participação em redes tecnológicas com instituições de P\&D e firmas de biotecnologia (GADELHA, 2002, TEMPORÃO, 2002 e BAETAS 2004).

No Brasil, o mercado de vacinas foi constituído por motivações ligadas à saúde pública e a história dos produtores nacionais está relacionada com desdobramentos de políticas governamentais, adotadas a partir da década de 70. O governo coordena a aquisição e distribuição gratuita das vacinas estabelecidas no calendário nacional de vacinação. 
Os principais produtores brasileiros são públicos. O Instituto de Tecnologia em Imunobiológicos - Bio-Manguinhos, da Fundação Oswaldo Cruz é vinculado ao Ministério da Saúde e Instituto Butantan, ligado ao Governo do Estado de São Paulo. Esses Institutos possuem linhas complementares de vacinas utilizadas no calendário básico de vacinação e seus produtos inovadores são frutos de acordos de transferência de tecnologia com empresas transnacionais, embora possuam grupos estruturados de P\&D.

Essas empresas buscam ampliação do mercado internacional de vacinas através de estratégias de lançamento continuado de novos produtos, o que possibilitou um crescimento de mais de 50\% em 3 anos, passando de 4 bilhões de dólares em 2004 para 9 bilhões de dólares em 2007. O Brasil se apresenta com um mercado público cujas aquisições, de produtores locais e empresas transnacionais, estão na ordem de 750 milhões de reais anuais. A presença dos produtores públicos locais, como suporte da política de imunizações, faz com que esses necessitem de capacitação tecnológica continuada para ampliar seu portfolio de produtos. Tal necessidade a curto prazo fez emergir alianças estratégicas com algumas empresas transnacionais.

Bio-Manguinhos é o maior produtor de vacinas da América Latina e o principal fornecedor da vacina contra a febre amarela para as agências das nações unidas. Em 2007, produziu mais de 100 milhões de doses de vacinas e forneceu $47 \%$ do quantitativo adquirido pelo Programa Nacional de Imunizações. O faturamento do Instituto neste ano foi equivalente a R $\$ 600$ milhões, somando o fornecimento de vacinas, biofármacos e reativos para diagnóstico. Esse desempenho se deve à introdução de novas vacinas e biofármacos de mais alto preço, produzidas através de acordos de transferência de tecnologia.

Visando atender às demandas geradas pelo quadro epidemiológico do país, através das políticas adotadas pelo Programa Nacional de Imunização (PNI), Bio-Manguinhos fez acordos de transferência de tecnologia para a produção de algumas vacinas que já existiam no mercado. Esses acordos foram necessários, visto que o desenvolvimento autóctone de uma vacina dura de 10 a 15 anos e o Instituto tem apenas 32 anos de existência.

Nos anos 70 aconteceu o primeiro processo de transferência de tecnologia, após uma grande epidemia de meningite meningocócica. Bio-Manguinhos produziu mais de 60 milhões de doses dessa vacina para o PNI e a pré-qualificação pela Organização Mundial de Saúde (OMS) vem possibilitando a exportação desse produto essa vacina, através das agências das Nações Unidas, para países do sub Saara africano, onde a doença é endêmica. O sarampo e poliomielite foram erradicados no Brasil com a produção local de vacinas, fruto de transferências de tecnologia ocorridas na década de 80. A introdução da vacina conjugada contra Haemophilus. influenzae tipo b - Hib, cuja produção é altamente complexa envolvendo processos biológicos e de química fina, ocorreu no final dos anos 90. Em 2003, o calendário de vacinação incorporou a vacina tríplice viral, 
contra sarampo, caxumba e rubéola. Por exigência do PNI, essa vacina deveria conter um determinado vírus menos reatogênico para a caxumba, que somente duas transnacionais o possuíam na composição vacinal. Atualmente, outros contratos de transferência de tecnologia estão em andamento. $\mathrm{Na}$ área de vacinas, a vacina contra Rotavírus, produzida por um vírus geneticamente modificado, foi introduzida no calendário de vacinação nacional em 2006 pelo PNI, incentivando o Instituto a assinar acordo para absorver essa tecnologia, ocorrido em 2008.

Para atender às necessidades dos programas nacionais de medicamentos de alto custo, de forma rápida, ampliar seu portfólio e aumentar sua capacitação tecnológica, o Instituto buscou parcerias com outras instituições que não as empresas transnacionais. Através da cooperação com produtores cubanos produz, desde 2004, os biofármacos eritropoetina e interferon, através de modernas técnicas de biologia molecular, com microorganismos geneticamente modificados e cultura de células diplóides transfectadas com o DNA a ser expresso.

Essas transferências de tecnologia permitiram que Bio-Manguinhos se constituísse na base tecnológica do Estado brasileiro para as políticas de saúde. Além disso, utilizando as mesmas plataformas tecnológicas absorvidas pode desenvolver internamente novos produtos necessários aos programas nacionais de saúde.

Para produzir efetivamente esses biológicos oriundos de tecnologias de ponta, a organização precisou desenvolver algumas competências. Entre elas, o desenvolvimento de uma gestão tecnológica com capacidade para viabilizar a apropriação da tecnologia adquirida. Entretanto, para gerar outras novas tecnologias são necessárias competências específicas para inovar.

Segundo Munier (1999), as competências ${ }^{1}$ para inovar podem ser classificadas em quatro tipos. As competências de "meios", que estão relacionadas à infra-estrutura, são as que permitem à empresa fazer P\&D, obter financiamentos e/ou vender a inovação. São as competências que permitem a mobilização dos recursos da empresa para desenvolver uma inovação e sua capacidade de arcar com os custos que resultam desse desenvolvimento. As competências tecnológicas, que se referem à habilidade de fazer uso efetivo do conhecimento tecnológico, estão relacionadas à gestão da produção e das tecnologias. As competências organizacionais são as que favorecem a criação de novos conhecimentos, segundo o modelo de Nonaka e Takeuchi (1997) e as formas de aprendizagem de Bell e Pavitt (1995). Essas últimas competências incluem a gestão de pessoas e a inovação nas empresas. As competências relacionais são aquelas que atuam sobre os mercados (relações com a concorrência e com a demanda) e que dizem respeito à capacidade da empresa em cooperar, formar alianças e se apropriar de tecnologias externas.

\footnotetext{
${ }^{1}$ Em inglês, são usados diferentes termos para competências, como capabilities, competence e competencies. Há uma vasta literatura que procura fazer a distinção entre os termos competências e capacidade tecnológica (FIGUEIREDO, 2004). Neste trabalho, o termo competências e capacidade são usados indistintamente.
} 
Estudando os processos de acumulação de competências tecnológicas de empresas em países em desenvolvimento, Lall (1992) e Bell e Pavit (1995) propuseram uma taxonomia para explicar o processo gradual de acumulação. Essa taxonomia consiste em uma matriz que relaciona as dimensões técnicas e organizacionais da empresa com níveis de complexidade, a partir de um estágio que reflete níveis mínimos de conhecimento necessários para operações de rotina até o estágio de capacidades inovadoras avançado.

Para Dutrénit (2002; 2004; 2007), o processo de acumulação de competência tecnológica, a partir dos primeiros estágios de capacidade rotineira até os estágios mais avançados de competência tecnológica inovadora, não é uma simples progressão linear. Ao contrário, é um processo de transição complexo em que as firmas têm que construir um profundo e vasto estoque de conhecimento e desenvolver novos tipos de conhecimento gerencial. Nessa fase de transição, a empresa ainda não possui as competências estratégicas para inovar. Possui o que a autora denomina de competências estratégicas embrionárias, que são competências estratégicas incipientes e não utilizadas para distinguir a firma competitivamente. Elas incluem um profundo conhecimento acumulado mais em algumas funções tecnológicas ou áreas do conhecimento tecnológico do que em outras, servindo de base para a formação das capacidades estratégicas.

Partindo da hipótese de que Bio-Manguinhos, através de o domínio de tecnologias de ponta proporcionado pelas transferências de tecnologia, desenvolveu as capacidades tecnológicas básicas e que as bases para a formação das capacidades estratégicas para atingir um grau inovador também dependem do desenvolvimento das competências organizacionais, as perguntas que se colocam são: a organização detém essas competências? Se as possui, estão desenvolvidas em que nível? É possível que a capacidade inovadora de Bio-Manguinhos esteja limitada por suas algumas deficiências organizacionais?

O presente trabalho tem como objetivo investigar se o Instituto possui as capacidades organizacionais, em que grau elas estão desenvolvidas e se esse desenvolvimento é fruto dos processos de parcerias de transferência de tecnologia ou somente de esforços próprios. O trabalho está dividido da seguinte forma: além dessa introdução. A sessão 2 refere-se à discussão da literatura que trata das competências da firma, na seção 3, apresenta-se a metodologia, os resultados são analisados e discutidos na seção 4 e na seção 5 apresentam-se as conclusões.

\section{Bases Teóricas}

Desde a revolução industrial, a capacidade tecnológica inovadora tem sido considerada como fator fundamental para o crescimento e fortalecimento econômico de longo termo nos países industrializados. Por meio de o lançamento de novos produtos ou processos que possibilitem a melhoria de produtos e o aumento de produtividade, as empresas desses países renovam sua 
capacidade tecnológica, as possibilitando manter vantagens competitivas no mercado (TEECE; PISANO; SHUEN, 1997). A partir de a década de 70, muitos estudos enfatizaram o papel da capacidade tecnológica como fonte de diferença entre setores industriais e países, no que se refere a progresso industrial e crescimento econômico no contexto de países industrializados (FREEMAN, 1982; ROSEMBERG, 1982; NELSON e WINTEr, 1982; DOSI, 1988a; 1988b; COHEN e LEVENTAL, 1989).

No inicio da década de 90, se começou a discutir o "conhecimento", a "capacidade específica da firma" e o "aprendizado" como fatores de vantagem competitiva da firma em economias industrializadas. Além de a abordagem baseada em recursos e a teoria evolucionista, utilizou-se, como fonte conceitual, o arcabouço de "capacidade dinâmica" (TEECE; PISANO; SHUEN, 1997; PRAHALAD; HAMEL, 1990); os conceitos do "aprendizado organizacional" e da criação do conhecimento na empresa (SENGE, 1990; NONAKA; TAKEUCHI, 1997); e outros tipos de aprendizado (ROSEMBERG, 1982 e VON HIPPEL, 1988). Os direitos de propriedade intelectual (TEECE, 1997) e o capital intelectual (STEWART, 1997) também fizeram parte dos estudos surgidos nesse período.

Esses estudos focavam tecnologia e inovação. Eles contribuíram muito para a compreensão da construção da capacidade tecnológica e aprendizado, como fonte de criação e sustentabilidade de vantagem competitiva de empresas que operam na fronteira tecnológica. No entanto, segundo Figueiredo (2002), tais estudos não são suficientes para cobrir os aspectos relacionados às empresas de países em desenvolvimento, emergentes ou em transição.

As empresas de países em desenvolvimento iniciam seus negócios a partir de tecnologia adquirida de empresas de outros países. Ao iniciar suas atividades, elas sequer dispõem de capacidades tecnológicas básicas, partem de condições não competitivas no mercado mundial e têm no acúmulo de capacidade tecnológica, para se manter nos mercados em desenvolvimento, um de seus problemas (KATZ, 1985; LALL, 1992; BELL; PAVITT, 1993 e 1995; KIM, 1997).

Para Bell e Pavitt (1993; 1995), a utilização de uma tecnologia envolve muito mais do que aquisição de equipamentos e assimilação de 'know-how' de operação. Na fase de investimento, esse uso envolve atividades criativas e complexas, gerando mudança técnica incremental para adaptar a tecnologia adquirida às condições específicas e, posteriormente, melhorias contínuas para atingir os desempenhos alcançados nos locais de origem. Os autores afirmam ainda que os usuários e adaptadores de tecnologia desempenham um papel significativo nos processos de mudança técnica contínua, não somente pelos efeitos positivos que a incorporação desta mudança em sistemas de produção provoca no mercado de fornecedores, mas também no processo de inovação em si. $\mathrm{O}$ investimento em nova planta demanda uma gama de serviços de engenharia, gerenciamento de projeto e fornecedores. A firma não exerce um papel passivo nessa interação, mas gera uma parte da 
tecnologia incorporada nas especificações, projetos de bens de capital e controla as decisões que envolvem a tecnologia a ser implantada. Portanto, a capacidade tecnológica não é somente acumulação de habilidades e 'know-how' para operação de novos processos ou produção conforme as especificações. Ela é acumulação de conhecimentos mais profundos, habilidades e experiência para gerar mudanças incrementais contínuas que melhorem o desempenho da tecnologia em uso e modifiquem os processos face às necessidades do mercado.

Bell e Pavitt (1993; 1995) fazem ainda a distinção entre duas fontes de recursos: capacidade de produção e capacidade tecnológica. A primeira incorpora os recursos usados para a produção industrial em dados níveis de eficiência e envolve o capital tecnológico embutido em equipamentos; a experiência e qualificação da mão de obra para operar e gerenciar o 'know-how'; as especificações dos produtos; os sistemas usados e; os métodos organizacionais.

A capacidade tecnológica consiste dos recursos necessários para gerar e gerir mudança técnica, incluindo habilidades, conhecimento e experiência, estrutura e redes institucionais. Nesse contexto, os autores reforçam a importância da acumulação tecnológica ou aprendizado tecnológico, que se refere a qualquer processo pelo qual são aumentados ou reforçados os recursos necessários para gerar e gerenciar a mudança técnica (capacidade tecnológica). Esse processo de acumulação é parte dos bens intangíveis da empresa e o investimento neste tem se tornado quantitativamente mais expressivo do que em capital fixo, principalmente em setores baseados em ciências.

A base dos processos de acumulação de capacidade tecnológica está no aprendizado organizacional, para imitar ou inovar, ocorrendo em dois níveis (KIM, 1999): nos indivíduos e na conversão do conhecimento individual em organizacional. Os primeiros atores do processo de aprendizado organizacional são os individuais dentro da firma, porém o processo não é o simples somatório do aprendizado individual, mas onde o conhecimento é criado, distribuído através de a organização, comunicado entre os membros desta, validado consensualmente e integrado na estratégia de gerenciamento da organização. Esse aprendizado individual é, portanto, uma condição indispensável para o aprendizado organizacional, mas não como condição suficiente. Kim (op. cit.) enfatiza que a organização aprende somente quando os "insights" e habilidades individuais se tornam incorporados nas rotinas organizacionais, práticas e crenças. Ou seja, o gerenciamento do processo de aprendizagem deve permitir que diferentes componentes internos sejam articulados para reforçar o processo de construção do conhecimento.

Vários autores (KATZ, 1985; LALL, 1992; BELL; PAVITT; 1993 e 1995; KIM, 1997) contribuíram para a construção gradual de um modelo analítico para entender o processo de acumulação de capacidade tecnológica por empresas de países de industrialização tardia. Baseado em estudos empíricos, uma taxonomia foi elaborada para explicar o processo gradual de 
acumulação, a partir de um estágio que reflete um nível mínimo de conhecimento necessário para as operações de rotina até o estágio mais avançado de capacidades inovadoras.

Lall (1992) categorizou as capacidades tecnológicas por funções técnicas. Construiu uma matriz em que nas linhas é possível visualizar que a capacidade tecnológica se acumula a partir de as categorias mais simples para as mais complexas. As colunas descrevem as principais funções técnicas que a empresa deve possuir a fim de garantir uma operação comercial bem sucedida. Esse conjunto ampliar-se-á à medida que a empresa for desenvolvendo tarefas mais complexas até que se torne tecnologicamente madura nas etapas mais avançadas. O nível básico indica se a firma possui competência para realizar as operações simples de rotina; definir seus planos de investimento; selecionar os equipamentos de processo; operar em níveis mínimos de eficiência em controle de qualidade e de manutenção dos equipamentos; melhorar custos ou adaptar seus produtos às mudanças de condições do mercado e; desenvolver parcerias com fornecedores. Essas competências básicas tendem a aumentar com o tempo, conforme a organização desenvolve atividades mais complexas, passando por um estágio intermediário com foco na adaptação e replicação de produtos até que a firma se torne tecnologicamente madura, inovadora em processos e produtos com capacidade avançada de investimento, produção e fortes elos na economia (fornecedores, empresas subcontratadas, intuições de tecnologia e outros).

Posteriormente, Bell e Pavitt (1995) acrescentaram a dimensão organizacional à matriz, deixando mais clara a ligação entre aprendizagem e acumulação de capacidade tecnológica, os processos envolvidos na acumulação e o papel dos fatores institucionais/organizacionais. Nessa "reforma" da matriz, esses autores ainda fazem distinção entre capacidade rotineira e capacidade inovadora. Como Lall (1992), classificam esta última em três níveis: básico, intermediário e avançado.

Este modelo foi adaptado por Figueiredo (2001 e 2003) para estudar a indústria do aço no Brasil, distinguindo sete níveis de capacidade tecnológica. Tal adaptação permitiu que a aplicação do modelo pudesse examinar a taxa de acumulação, isto é, o número de anos que uma empresa leva para alcançar certo nível de capacidade para funções tecnológicas específicas. Esta métrica vem sendo modificada e sua aplicação empírica usada por vários autores para estudar diferentes empresas ou setores industriais ${ }^{22}$.

Para Dutrénit (2002, 2004 e 2007), a aplicação deste modelo tem gerado muito conhecimento de como as empresas se movem a partir de capacidades rotineiras para capacidades inovadoras básica, intermediária e avançada, porém não permite a compreensão do processo de transição atravessado pelas firmas para deterem as competências essenciais ("core competences").

\footnotetext{
${ }^{2}$ Ver Dutrénit (2007) e Figueiredo (2007) para uma ampla revisão sobre a aplicação desta métrica.
} 
Nesta transição, as firmas já acumularam conhecimento e construíram as bases mínimas essenciais de capacidade tecnológica, estão próximo da fronteira internacional do conhecimento em algumas áreas, porém em outras funções ainda carecem de fortalecimento. Detêm, o que a autora chama, capacidades embrionárias.

Ainda, segundo Dutrénit (2002, 2004 e 2007), o processo de transição traz novos desafios de aprendizagem. Ela ressalta a importância do processo de aprendizagem a partir de fontes externas, envolvendo os processos de socialização e codificação dos conhecimentos mais básicos para a construção de uma base mínima de conhecimento. No processo de transição, as organizações devem construir, aprofundar e alargar seus estoques de conhecimento e desenvolver formas de gestão do conhecimento. Elas devem aprender a gerenciar novos processos organizacionais tais como a conversão da aprendizagem individual em aprendizagem organizacional. A coordenação das estratégias de aprendizagem implementadas por diferentes unidades dentro da organização pode seguir diferentes lógicas de acumulação e o processo de criação do conhecimento para a construção de bases complexas pode ficar comprometido. A fraqueza neste processo organizacional dificulta a formação de competências estratégicas e a compleição do processo de transição.

\section{Metodologia}

\subsection{Proposta de avaliação das competências organizacionais}

As competências organizacionais são necessárias para a formação de capacidades estratégicas para inovar. Estas envolvem uma gestão tecnológica que seja altamente especializada e vislumbre estratégias administrativas que viabilizem a apropriação e internalização nos diversos segmentos das empresas de processos tecnológicos adquiridos ou gerados.

François e colaboradores (1999) desenvolveram um questionário para identificar as competências para inovar no âmbito da indústria francesa. A essência do questionário é perguntar aos responsáveis pelas empresas se estas possuem aptidões e rotinas operacionais pré-definidas, que sejam as bases para a inovação, e em que grau estes procedimentos estão implantados na organização. A abordagem é bastante ampla e permite avaliar empresas de segmentos diferentes dentro das indústrias, viabilizando não somente a comparação entre elas, como também entre países e os pontos fracos nos seus Sistemas Nacionais de Inovação.

No Brasil, alguns estudos foram desenvolvidos com base no questionário de François e colaboradores (1999) para avaliar indústrias brasileiras. Alves, Bomtempo e Coutinho (2005), por exemplo, modificaram o questionário com o intuito de estudar as competências para inovar na indústria petroquímica brasileira. Alves (2005) também utilizou esta mesma adaptação do questionário para avaliar, com utilização de métodos estatísticos, as competências para inovar na indústria de embalagens que operam no Brasil. Baetas (2004) e Bomtempo e Baetas (2005) 
adaptaram o questionário para avaliação da indústria brasileira de vacinas. Em todos esses trabalhos foi possível avaliar um conjunto das chamadas - competências para inovar -, que estariam presentes em maior ou menor grau nessas indústrias.

Embora a abordagem seja a inovação como finalidade e a identificação das aptidões que a empresa deve deter para que a inovação ocorra e seja rentável, uma adaptação nesse questionário permitiu avaliar em que grau as competências estão implantadas nas empresas como rotinas de inovação. Nesse ponto, podemos fazer uma analogia às concepções de Lall (1992), Bell; Pavitt (1993 e 1995) no que se refere à acumulação de competências pelas organizações em níveis ou graus de complexidade, mais especificamente no que se refere às competências organizacionais definidas por Munier (1999).

Portanto, é possível adaptar as questões do questionário para avaliar mais profundamente o grau de desenvolvimento essas competências, em uma organização baseada em ciências, que opera em país de industrialização tardia.

A pesquisa foi realizada através de um questionário enviado a todas as pessoas com formação universitária que trabalham no Instituto, sem distinção de hierarquia ou área de atuação. Como ponto de partida, utilizou-se a proposta de François et al (1999) para identificar as competências organizacionais detidas pela empresa e avaliar em que grau essas competências estão implantadas como práticas utilizadas para facilitar o processo de inovação. Da proposta foram consideradas apenas as variáveis que avaliam tais competências, adaptadas para as organizações produtoras de imunobiológicos no Brasil.

No que tange às questões relativas às formas de aquisição/geração de conhecimento organizacional e os mecanismos de socialização e codificação do conhecimento, as variáveis foram inspiradas nas questões levantadas para a indústria do aço (FIGUEIREDO, 2002 e 2007) e para o processo de formação de capacidades essenciais para uma indústria de vidro. (DUTRÉNIT, 2002, 2004 e 2007).

\subsection{Seleção da amostra}

O critério de inclusão elegeu pessoas com nível de instrução superior para responderem ao questionário. Essa força de trabalho representa 50\% dos profissionais de Bio-Manguinhos à época da pesquisa. Como critério de exclusão, estabeleceu-se pessoas com menos de um ano de trabalho na organização ou pessoas que, por algum motivo, estavam fora da instituição - férias, trabalho externo, congressos e outros - no mês de dezembro de 2007.

A partir desses critérios, enviou-se 306 questionários que representaram uma amostra de $64 \%$ da força de trabalho com nível superior. Obteve-se 94 questionários respondidos, configurando-se $31 \%$ dos formulários enviados. 


\subsection{Construção do questionário}

O questionário foi elaborado desdobrando-se as competências organizacionais em oito blocos de competências complexas: "Inserção da inovação na estratégia da organização (Bloco 1) ; "Mecanismos de apropriação de tecnologia e conhecimento externo" (Bloco 2); "Geração de conhecimento" (Bloco 3); "Estratégias de socialização do conhecimento" (Bloco 4); "Estratégias de codificação do conhecimento (Bloco 5); “Gestão e proteção da propriedade intelectual” (Bloco 6); "Gestão dos recursos humanos em uma perspectiva de inovação" (Bloco 7) e; "Formas de financiamento e cooperação para a inovação" (Bloco 8).

Cada uma dessas competências complexas é composta de várias competências operacionais. Nos oito blocos de competências complexas que formam as competências organizacionais para inovar, foram consideradas 58 competências operacionais. O Quadro 1 é um exemplo da formação de um desses blocos de competências complexas.

Quadro1

Mecanismos de apropriação de tecnologia e conhecimento externo

\begin{tabular}{|c|c|c|c|c|c|}
\hline Formas de apropriação de tecnologias e conhecimentos por Bio-Manguinhos (Bloco 2) & 0 & 1 & 2 & 3 & 4 \\
\hline Parcerias, desenvolvimento conjunto? & & & & & \\
\hline Compra de Tecnologia? & & & & & \\
\hline Promove palestras com especialistas? & & & & & \\
\hline Facilita o acesso a trabalhos científicos, relatórios e outras fontes de informação? & & & & & \\
\hline Utiliza o sistema de patentes como forma de informação tecnológica? & & & & & \\
\hline Possibilita a participação em cursos técnico-especializados de curta ou longa duração? & & & & & \\
\hline Possibilita a participação em Cursos de Mestrado e Doutorado? & & & & & \\
\hline $\begin{array}{l}\text { Possibilita a participação em visitas e observações a outras Unidades Organizacionais } \\
\text { de BM? }\end{array}$ & & & & & \\
\hline Possibilita a participação em visitas e observações a Instituições/organizações? & & & & & \\
\hline Possibilita a participação em Congressos, Simpósios e Seminários? & & & & & \\
\hline
\end{tabular}

Fonte: elaboração própria

Nesse exemplo, 10 questões objetivas permitem cinco respostas identificadas de 0 a 4 , correspondendo de forma crescente à: não sei responder; não - significando que tal competência não está presente na organização; presente em algumas áreas sem procedimentos formais; presente com procedimentos formais pouco disseminados na organização; presente com procedimentos formais amplamente disseminados na organização. Os graus 2, 3 e 4 podem ser classificados nível básico, intermediário e avançado, respectivamente, conforme classificação de Lall (1992) e de Bell e Pavitt (1993 e 1995). Esse procedimento se repete nos demais grupos.

Apesar de o respondente manter-se anônimo, o questionário incluiu perguntas de múltipla escolha permitindo identificar o seguinte perfil do funcionário: departamento ou assessoria em que desenvolve suas atividades; tempo de trabalho na instituição; titulação e; se ocupa cargo de chefia. O questionário foi validado por um grupo de especialistas da área de inovação e gestão tecnológica, 
sendo um professor universitário, um alto funcionário de uma grande empresa estatal e um funcionário de uma agência de fomento à pesquisa.

\section{4 - A coleta de dados}

A seleção dos participantes abrangeu diferentes níveis hierárquicos de funcionários, incluindo diretores, assessores, gerentes de departamentos, laboratórios, seções, coordenadores de áreas ou projetos ou apenas funcionários sem cargo de gestão. Os questionários foram enviados por malote aos destinatários, em envelopes lacrados, solicitando retorno no prazo de uma semana pela mesma via, sem necessidade de identificação do remetente. As respostas recebidas alimentaram um banco de dados no programa Excel. Este banco de dados foi importado para o programa Statistical Package for Social Science (SPSS), que gerou os dados percentuais e estatísticos das respostas.

\section{Análise e discussão dos resultados}

Os resultados obtidos serão analisados sob dois aspectos. No primeiro, serão discutidas as competências organizacionais globais e agrupadas, segundo os oito grupos de competências complexas. No segundo aspecto, serão comparadas as competências organizacionais ligadas à aquisição do conhecimento individual e sua conversão em conhecimento organizacional, conforme classificam Bell; Pavitt (1993 e 1995), Nonaka e Takeuchi (1997), Kim (1999) e Dutrénit (2002, 2004 e 2007), com as demais competências. Inicialmente, traça-se o perfil dos respondentes, segundo área de atuação, grau de formação e tempo de trabalho na Instituição.

\subsection{Perfil dos respondentes}

A maioria dos respondentes (32\%) atua na área de produção (VPROD), seguidos dos colaboradores da área de gestão $(\mathrm{VGEST})^{3} \operatorname{com} 31 \%$, da área de qualidade (VQUAL) com 20\% e das áreas de desenvolvimento tecnológico (VDTEC) com 13,8\% e Assessorias (ASSET) com 3\%. Estes percentuais correspondem proporcionalmente ao número de pessoas das respectivas áreas, ou seja, existem mais pessoas lotadas nas áreas de produção; seguidas das áreas de gestão, que inclui a parte de manutenção e operação de utilidades; e assim sucessivamente.

Através das respostas observou-se que $86 \%$ dos funcionários têm algum curso de especialização, sendo que destes $29 \%$ possuem o título de mestre e $11 \%$ são doutores. Das pessoas com doutorado, 50\% trabalham nas áreas de Desenvolvimento Tecnológico e os demais estão lotados nas Assessorias (10\%), nas áreas de Produção e de Gestão. A Vice Diretoria de Qualidade não teve nenhum respondente com doutorado e o número de pessoas com mestrado é apenas $5 \%$

\footnotetext{
${ }^{3}$ A vice-diretoria de qualidade engloba os departamentos de controle de qualidade e garantia de qualidade, que incorpora também as atividades de metrologia e validação. A vice-diretoria de gestão é formada pelas áreas de logística, administração, relações com o mercado e as áreas de engenharia e manutenção. As assessorias estão ligadas à direção ou às vices diretorias
} 
menor que aquelas pertencentes às áreas de produção e desenvolvimento tecnológico (30\% cada), porém maior que o número de pessoas da VGEST (14\%).

Quanto ao tempo de trabalho na organização, 62\% das pessoas com algum tipo de pósgraduação trabalham na unidade há menos de 8 anos, sendo que metade destas foi contratada nos últimos dois anos.

\subsection{Análise das competências organizacionais e das competências complexas}

A Tabela 1 apresenta a nota média global obtida pelo Instituto para as competências organizacionais. $\mathrm{O}$ valor representa a média das 58 competências operacionais, que compõem os oito grupos de competências complexas. Esses resultados sugerem que as competências organizacionais, de uma maneira geral, estão pouco desenvolvidas, mas que já foram consolidadas no seu nível básico e estão evoluindo para o nível intermediário. Segundo Dutrénit (2002; 2004 e 2007), no processo de transição, mesmo que a organização tenha atingido seu nível avançado nas competências tecnológicas, ela não será capaz de desenvolver as competências essenciais se as organizacionais não estiverem suficientemente desenvolvidas.

Tabela 1

Competências organizacionais para inovar (nota média global, máximo 4)

\begin{tabular}{|l|c|c|c|c|}
\hline & Média & Mínimo & Máximo & $\begin{array}{c}\text { Desvio } \\
\text { padrão }\end{array}$ \\
\hline $\begin{array}{l}\text { Competências } \\
\text { organizacionais }\end{array}$ & 2,55 & 1,00 & 4,00 & 0,6681823 \\
\hline
\end{tabular}

Pela nota máxima (4) e mínima (1) atribuídas pelos respondentes às competências operacionais, pode-se observar que o grau de desenvolvimento delas parece ser muito heterogêneo na instituição. Segundo os critérios definidos por Lall (1992) e Bell e Pavit (1995), algumas podem não existir ainda, ao passo que outras se encontram no nível avançado. Portanto, para se ter uma idéia dos pontos fortes e fracos das competências organizacionais para inovar do Instituto é preciso uma análise individual das competências complexas. A seguir, faz-se uma análise descritiva das competências com os valores médios mais elevados e os mais baixos.

A tabela 2 apresenta as notas médias obtidas para cada uma das competências complexas analisadas. Da mesma forma, os valores representam as médias das competências operacionais que caracterizam cada um dos oito grupos de competências complexas. Pode-se observar que as competências para "apropriação de tecnologia e conhecimento externo" se destacam, sendo as competências que se encontram desenvolvidas em um nível intermediário. Isso pode denotar que os respondentes reconhecem o esforço da Instituição na busca de tecnologias que não detém e no investimento em treinamentos e participação em eventos técnico-científicos. O Instituto, através de 
sua Vice-diretoria de Desenvolvimento Tecnológico, promove palestras semanais com especialistas internos e externos, criou o seu próprio curso de Mestrado Profissional em parceria com o Instituto Oswaldo Cruz e um MBA em Gestão de Imunobiológicos em parceria com a COPPE/UFRJ. Além disso, por estar inserido em uma instituição de pesquisa (Fiocruz), há mais facilidade para as pessoas buscarem informações científicas, participar de cursos de especialização, mestrado e doutorado.

As outras competências que parecem já estar desenvolvidas no nível básico e estão evoluindo para o nível acima são àquelas relacionadas à formação do conhecimento organizacional: "geração do conhecimento interno", "socialização do conhecimento" e a "codificação do conhecimento". Essas já estão pelo menos na metade da trajetória entre o nível básico e intermediário, sendo que a última é a mais desenvolvida, seguida das competências para "socialização do conhecimento" e para "geração do conhecimento interno", respectivamente. O nível de desenvolvimento das competências relacionadas à codificação do conhecimento ainda é baixo para uma organização que, por sua natureza é regulada por órgãos que exigem o cumprimento das Boas Práticas de Fabricação, em que todas as atividades produtivas e relativas à qualidade devem seguir procedimentos operacionais padrão (POP). Esse resultado é o reflexo das respostas de pessoas atuantes em todas as áreas da organização, podendo não refletir a realidade das áreas finalísticas (produção e qualidade) inspecionadas anualmente, pelas autoridades regulatórias.

Essa seqüência do nível de desenvolvimento das competências relacionadas às formas de conversão do conhecimento individual em institucional sugere que há deficiência em dois mecanismos significativos: "a socialização do conhecimento" e a "geração do conhecimento interno". No primeiro caso, a instituição pode ainda não possui as competências operacionais difundidas em toda a organização no que diz respeito a treinamentos internos, rodízios em atividades ou tarefas, reuniões com freqüência regular envolvendo as áreas de produção e desenvolvimento tecnológico ou a realização de seminários internos para a socialização das informações obtidas em eventos externos. As competências operacionais que formam as competências complexas "geração do conhecimento interno" sugerem que a organização pouco incentiva a formulação de novas idéias, embora o Instituto reconheça, formal e anualmente, o profissional que se destaca em sua área de atuação. A avaliação individual à produção do conhecimento coletivo não é suficientemente valorizada e o grau de autonomia para inovar ainda é baixo. Também podem significar que o incentivo a estudos de melhorias de rotinas operacionais, melhoria de processos e ao desenvolvimento de novos processos para produtos existentes não faz parte da cultura organizacional. Essas fraquezas, se existentes, segundo Dutrénit (2002; 2004 e 2007), comprometem a consolidação das bases do conhecimento necessárias à formação das competências embrionárias, gerando um ambiente pouco propício à inovação. Estes resultados 
representam a visão de 94 pessoas de diferentes áreas e níveis hierárquicos, que podem não ter uma visão mais ampla da Organização.

A Tabela 2 mostra que as competências complexas menos desenvolvidas são: "gestão e proteção da propriedade intelectual", "gestão de recursos humanos em uma perspectiva de inovar", "financiamento e cooperação para inovar" e, com grau maior neste grupo, "a inserção da inovação na estratégia da organização". O nível de desenvolvimento das competências complexas "gestão e proteção da propriedade intelectual" parece não ter atingido o nível básico, podendo significar que a organização não identifica conhecimentos e "know how" estratégicos, não controla a comunicação sobre conhecimentos estratégicos, não motiva as pessoas com conhecimentos estratégicos e não garante a conservação máxima do conhecimento estratégico do indivíduo com sua saída. Essa avaliação é menor do que o resultado encontrado por Baetas (2004) e Bomtempo e Baetas (2005), ao observarem a necessidade de maior atenção sobre essa dimensão. Em relação às duas primeiras competências operacionais deste bloco, a melhoria de seus níveis poderia estar relacionada a questões administrativas internas à organização. No entanto, as outras duas sugerem refletir a inadequação do regime jurídico a que está submetido o Instituto (serviço público), que determina procedimentos muito pouco flexíveis para uma organização que busca competir na fronteira do conhecimento.

Tabela 2

Competências complexas que compõem as competências organizacionais

\begin{tabular}{|l|c|c|c|c|}
\hline \multicolumn{1}{|c|}{ Competências Complexas } & Média & Mínimo & Máximo & $\begin{array}{c}\text { Desvio } \\
\text { padrão }\end{array}$ \\
\hline 1 - Inserção da inovação na estratégia da organização & 2,31 & 1,00 & 4,00 & 0,882479 \\
\hline $\begin{array}{l}\text { 2 - Mecanismos de apropriação de tecnologia e } \\
\text { conhecimento externo }\end{array}$ & 3,00 & 1,00 & 4,00 & 0,604642 \\
\hline 3 - Geração de conhecimento interno & 2,50 & 1,00 & 4,00 & 0,772512 \\
\hline 4 - Estratégias de socialização do conhecimento & 2,62 & 1,00 & 4,00 & 0,765072 \\
\hline 5 - Codificação do conhecimento & 2,73 & 1,00 & 4,00 & 0,906079 \\
\hline 6 - Gestão e proteção da propriedade intelectual & 1,86 & 1,00 & 4,00 & 0,874994 \\
\hline $\begin{array}{l}\text { 7 - Gestão dos recursos humanos em uma perspectiva } \\
\text { de inovação }\end{array}$ & 2,06 & 1,00 & 4,00 & 0,959486 \\
\hline 8 - Financiamento e Cooperação para inovar & 2,11 & 1,00 & 4,00 & 0,897644 \\
\hline
\end{tabular}

Fonte: elaboração própria

Os resultados indicam que as competências "gestão de recursos humanos em uma perspectiva de inovar" se encontram no nível básico de desenvolvimento e podem traduzir que organização não identifica especialistas no atual e no futuro mercado de trabalho. Essa provável fraqueza pode estar relacionada com o modelo de gestão, em que a remuneração é determinada por um plano de cargos e salários instituído pelo governo federal, inferior ao mercado. Outro ponto que deve merecer atenção é a avaliação do desenvolvimento individual e de equipes, que segue normas subjetivas definidas em consonância com as orientações da direção central da Fiocruz, sem distinção do tipo de atividade e grau de complexidade. Os resultados dessas competências nesse 
trabalho também são mais pessimistas do que os relatados por Baetas (2004), onde os dirigentes do Instituto atribuíram um grau mais elevado, embora a escala de avaliação e o instrumento de pesquisa sejam diferentes.

As competências complexas "financiamento e cooperação para inovar" parecem estar consolidadas no nível básico. Isso pode influir no curso dos projetos e representar sua descontinuidade face à possível sub-alocação de recursos, pela não avaliação sistemática de custos à priori. Por outro lado, a possível não avaliação a posteriori dos projetos poderá impactar na previsão orçamentária de projetos futuros, tornando a inovação ou expansão muito mais lenta ou inviável durante seu curso. Da mesma forma, a busca de parceiros para o desenvolvimento de novos produtos ou melhoria dos existentes, assim como fraca iniciativa de desenvolver fornecedores de equipamentos e insumos, é um outro entrave à inovação. Nesse ponto, porém, há que se considerar as peculiaridades de uma indústria de imunobiológicos localizada em um país de industrialização tardia, onde a indústria é incipiente para atender as especificações mais nobres no que diz respeito à qualidade dos insumos, materiais e à existência de "softwares" validáveis. Esses fatores somados contribuem para que o processo de inovação em imunobiológicos seja mais difícil do que o realizado em empresas privadas de países industrialmente desenvolvidos. Somente nos últimos é que o governo brasileiro, através do Ministério da Saúde, vem incentivando essas parcerias.

As competências operacionais que constituem as competências complexas "a inserção da inovação na estratégia da organização" parecem estar um pouco mais desenvolvidas que as três anteriores, se deslocando para o nível intermediário de modo mais tímido do que aquelas relacionadas à formação das bases do conhecimento organizacional. Elas refletem o esforço da organização em avaliar novos formatos organizacionais, estruturar-se em torno de projetos de inovação, favorecendo o trabalho em equipe e priorizando os serviços necessários desde o início. Esses esforços podem estar muito mais direcionados aos projetos de expansão, que envolvam a absorção de tecnologia externa incorporada para o atendimento às demandas de saúde pública nacional, do que relacionados aos programas de desenvolvimento tecnológicos internos.

Para verificar se as possíveis diferenças encontradas entre o maior e menor grau atribuído às competências complexas são estatisticamente significantes, foram realizados os testes de hipótese nula entre o bloco que possui a maior média e o que possui a menor média com todos os outros. Também se testou a hipótese de que o bloco 8 não seria estatisticamente diferente do bloco 1. A rejeição da hipótese nula indicaria entre quais blocos existe uma diferença estatisticamente significativa no nível das competências. 
Tabela 3

Teste de hipóteses segundo as competências mais e menos desenvolvidas em relação às demais (os valores em negrito são significativos para $\mathrm{p}<0,05000$ )

\begin{tabular}{|l|l|l|l|}
\hline Competências & Bloco 2 & Bloco 6 & Bloco 8 \\
\hline Bloco 1 & 0,000000 & 0,000000 & $\mathbf{0 , 1 0 2 9 5 4}$ \\
\hline Bloco 2 & 1,000000 & 0,000000 & 0,000000 \\
\hline Bloco 3 & 0,000002 & 0,000000 & 0,001501 \\
\hline Bloco 4 & 0,00128 & 0,000000 & 0,000059 \\
\hline Bloco 5 & 0,018952 & 0,000000 & 0,000004 \\
\hline Bloco 6 & 0,000000 & 1,000000 & 0,059985 \\
\hline Bloco 7 & 0,000072 & $\underline{\mathbf{0 , 1 3 2 9 5 8}}$ & $\mathbf{\mathbf { 0 , 7 5 3 8 7 4 }}$ \\
\hline Bloco 8 & 0,000000 & $\underline{\mathbf{0 , 0 5 9 9 8 5}}$ & 1,000000 \\
\hline
\end{tabular}

\footnotetext{
Legenda:

Bloco 1 - Inserção da inovação na estratégia da organização

Bloco 2 - Mecanismos de apropriação de tecnologia e conhecimento externo

Bloco 3 - Geração de conhecimento interno

Bloco 4 - Estratégias de socialização do conhecimento

Bloco 5 - Codificação do conhecimento

Bloco 6 - Gestão e proteção da propriedade intelectual

Bloco 7 - Gestão dos recursos humanos em uma perspectiva de inovação

Bloco 8 - Financiamento e Cooperação para inovar
}

De acordo com os resultados mostrados na Tabela 3, a hipótese nula é rejeitada para uma função de probabilidade estatística menor que 5\% quando se compara as competências "Mecanismos de apropriação de tecnologia e conhecimento externo" com as demais. Isso significa que há diferença estatisticamente significativa entre estas e as demais, mesmo se consideramos uma função de probabilidade maior que $90 \%$. Os resultados da Tabela 3 mostram ainda que não há diferença estatisticamente significativa entre as competências do bloco 6 e as dos blocos 7 e 8 . Esta última, por sua vez, também não é estatisticamente diferente do bloco 1, confirmando a hipótese estabelecida.

Os resultados sugerem que as competências organizacionais para inovar no Instituto podem ser classificadas em dois grandes grupos. Um mais desenvolvido está relacionado à aquisição de conhecimento e tecnologias externas e sua conversão em conhecimento organizacional (Blocos 2 a 5); e o menos desenvolvido (Blocos 1, 6, 7 e 8) está ligado às demais competências organizacionais.

Para melhor verificar esta observação, calculou-se as notas médias obtidas para cada uma das competências operacionais, que compõem os dois grandes grupos mencionados acima.

\section{Tabela 4}

Competências organizacionais para inovar (nota média global, mínimo 1, máximo 4)

\begin{tabular}{|c|c|c|c|c|}
\hline $\begin{array}{c}\text { Grandes Grupos de } \\
\text { Competências }\end{array}$ & Média & Mínimo & Máximo & $\begin{array}{c}\text { Desvio } \\
\text { padrão }\end{array}$ \\
\hline Blocos 2 a 5 & 2,69 & 2,00 & 4,00 & 0,656262 \\
\hline Blocos 1, 6, 7 e 8 & 2,18 & 1,00 & 4,00 & 0,802721 \\
\hline
\end{tabular}


A Tabela 4 comprova que as médias entre estes dois grandes grupos de competências são muito diferentes $(p=0,000004)$. Enquanto as competências globais relacionadas ao conhecimento já consolidaram o nível básico e estão se deslocando para o nível intermediário, o outro grupo de competências organizacionais pode ainda se encontrar no nível básico. Observa-se também que não foi atribuído um grau inferior a 2 às competências complexas relacionadas ao conhecimento, significando que de algum modo estão presentes em todas as áreas da organização. Por outro lado, o grau 1 foi atribuído às demais competências organizacionais complexas, sugerindo que em algumas áreas não há a percepção de que elas existem.

\section{Conclusão}

Este trabalho apresentou uma proposta de avaliação das competências organizacionais para inovar, objetivando medir o grau de desenvolvimento dessas competências em Bio-Manguinhos.

Embora esse trabalho possa ter a limitação de que, provavelmente, parte dos respondentes não tenha uma visão geral da organização ou não estejam familiarizados com a definição de inovação ${ }^{4}$ utilizada, os resultados obtidos estão, de certa forma, alinhados com outras pesquisas realizadas por Baetas (2004), Bomtempo e Baetas (2005) e Baetas et al (2007). Pode-se considerar que a proposta foi validada considerando que a visão geral dos respondentes ao questionário, sobre o desenvolvimento de capacidades organizacionais, difere pouco daquela expressa pelos seus dirigentes traduzida nesses trabalhos citados.

A análise dos questionários permitiu verificar que o Instituto tem investido fortemente na aquisição de tecnologias externas e conhecimento externo. A compra de tecnologias mais modernas para a produção de imunobiológicos, para atender a tempo às demandas de saúde pública nacional, implica no forte investimento em treinamento de seus colaboradores nas atividades produtivas de quem vende tecnologia, seja nas áreas de produção, engenharia, controle e garantia de qualidade. Isso permite que a organização aprenda a adaptar e desenvolver melhorias nos processos envolvidos nessas funções técnicas, o que não exclui o desenvolvimento tecnológico autóctone de se beneficiar de novas plataformas tecnológicas. Os investimentos na aquisição de conhecimento não se limitam a esses tipos de treinamento, uma vez que o Instituto também propicia a efetiva participação de seus integrantes em cursos, simpósios, congressos, seminários técnicos, cursos de especialização, mestrado e doutorado. Todo esse esforço parece ainda não se traduzir, mais sistematicamente, na conversão do conhecimento individual em conhecimento organizacional, haja vista que esse não é o somatório dos conhecimentos individuais, mas sua conversão em rotinas operacionais.

\footnotetext{
${ }^{4} \square$ O Manual de Oslo (2005) define inovação como a implementação de um novo produto (bem ou serviço), de um processo novo ou significativamente melhorado, de um novo método de mercado (marketing), de um novo método organizacional nas práticas de negócios, ou de relações externas, para a empresa.
} 
Verificou-se que as competências organizacionais que não estão relacionadas ao conhecimento podem se encontrar menos desenvolvidas. Assim, algumas rotinas organizacionais ainda não atingiram o nível básico e outras, também fundamentais para a articulação da inovação, estão apenas desenvolvidas em seu nível mínimo. O desenvolvimento de competências organizacionais em nível pouco avançado pode comprometer os projetos de inovação da Instituição e não permitir que venha desempenhar um papel mais significativo no cenário mundial de produtores de imunobiológicos.

A visão que emerge deste trabalho é a de que o Instituto investe muito mais nas competências relacionadas à aquisição do conhecimento, em suas diversas formas, seguida da conversão deste em conhecimento organizacional, embora em menor grau. Indica também que uma maior atenção deve ser dada às outras dimensões das competências organizacionais que articulam os processos de inovação.

A partir dessas considerações, as perguntas que se colocam para estudos futuros são: Quais são as opções possíveis para o Instituto ampliar as competências organizacionais? 1) São questões que podem ser resolvidas no nível gerencial? 2) Ou a situação apresentada pode refletir a inserção de Bio-Manguinhos, como foco nas políticas governamentais e menor atuação internacional, ou mesmo o regime jurídico a que a está submetido, entre outras questões de natureza macro? Esse estudo também deve ser aprofundado com vistas a avaliar se a visão ora apresentada independe do nível hierárquico e da área de atuação dos respondentes.

\section{Referências}

Alves, F. C.; BOMTEMPO, J. V.; COUTINHO, P. L. A. Competências para Inovar na Indústria Petroquímica Brasileira. Revista Brasileira de Inovação, v. 4, n. 2, p. 301-327, 2005.

BAETAS, R. B. G. Modelo de Análise de Indústria Baseada em Ciências: O caso da indústria brasileira de vacinas de uso humano. 2004. 213 f. Tese (Doutorado em Processos Químicos e Bioquímicos) - Escola de Química, Universidade Federal do Rio de Janeiro.

BAETAS, R. B.G.; BOMTEMPO, J.V.;QUENTAL C. - Gestão da Inovação em Vacinas em Inovação em Saúde, Ed. Fiocruz, p. 375-396, 2007

BELL, M.; PAVITT, K. The development of technological capabilities. In: HANQUE, I. U., Technology and International Competitiveness. Washington: Trade/The World Bank, 1995. p. 69-101

. Technological Accumulation and Industrial Growth: Contrasts between Developed and Developing Countries. Industrial and Corporation Chance, v. 2, n. 2 p.157-211, 1993.

BOMTEMPO, J. V; BAETAS, R. B. G. Desenvolvimento de Vacinas no Brasil: uma análise da potencialidade de P\&D e estratégias de inovação. In BUSS, Paulo Marchiori (org). Vacinas, Soros \& Imunizações no Brasil. Rio de Janeiro: Editora Fiocruz, 2005.

COHEN, W.; LEVINTHAL, D. Absorptive Capacity: A New Perspective on Learning and Innovation. Administrative Science Quaterly, v. 35, n. 1, p. 128-152, 1990.

cross ${ }^{\text {ref }}$ 
DOSI, G. . The nature of the innovative process. In: DOSI, G.; FREEMAN, C.; NELSON, R.; SILVERBERG, G.; SOETE, L. Technical change and economic Theory. London: Pinter Publishers, 1988b.

. Sources, Procedures and Microeconomics Effects of Innovation. Journal of Economics Literature, v. 26, p. $\overline{1.120-71}, 1988 \mathrm{a}$.

DUTRÉNIT, G. Learning and knowledge management in the firm: from knowledge accumulation to strategic capabilities. Cheltenham: Edward Elgar, 2000.

Building Technological Capabilities in Latecomer Firms: A Review Essay. Science, Technology \& Society, v.9, $\mathrm{n}^{\mathrm{o}}$ 2, p.209-241, 2004.

The Transition from Building-up Innovative Technological Capabilities to Leadership by Latecomer Firms. Asian Journal of Technology Innovation, v.9, nº 2, p.125-149, 2007.

FIGUEIREDO, P. N. Aprendizagem Tecnológica e performance competitiva. Rio de Janeiro: FGV, 2003.

What Recent Research Does and Doesn't Tell Us about Rates of Latecomer Firms' Capability Accumulation. Asian Journal of Technology Innovation, v.9, nº 2, p.161-195, 2007.

Does technological learninig pay off? Implications for inter-firm differences in operational performance improvement. Research Policy, v. 31, no 1, p. 73-94, 2002.

FRANÇOIS, J. P.; GOUX, D; GUELLEC, D.; KABLA, I. ; TEMPLÉ, Ph. Décrire les competénces pour l'innovation: une proposition d'enquête. In Foray, D; Mairesse, J. (orgs), Innovations et performances, approaches interdisciplinaires, Paris: Éditions EHESS, 1999.

FREEMAN, C. The economics of industrial innovation. London: London Printer, 1982.

GADELHA, C. A. G. O complexo Industrial da Saúde e a Necessidade de um enfoque dinâmico na economia da saúde. Ciência \& Saúde Coletiva, Rio de Janeiro, v. 8, n.2, p. 521-35, 2002.

KATZ, J. Domestic technological innovations and dynamics comparative advantages: further reflections on comparative case-study program. In: ROSENBERG, N.; FISCHTAK, C. (Org.). International Technology Transfer Concepts, Measures, and Comparisons. Nova York: Praeger Publishers, 1985.

KIM, Linsu. Building techonological capability for industrialization: analytical frameworks and Korea's experience. Industrial and Corporate Change, Oxford, v. 8, n. 1, p. 111-36, mar. 1999.

From imitation to innovation: the dynamics of Korea's Technological Learning. Boston: Harvard

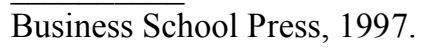

LALL, S.. Technological capabilities and industrialization. World Development, Oxford, v. 20, n. 2, p.165-86, Fev. 1992.

cross ${ }^{\text {ref }}$

MUNIER, F. Taille de la Firme et Innovation: appoches theóriques et empiriques fondées sur le concept de compétence. 1999. Tese (Doutorado em Ciências Econômicas) - Estrasburgo: Université Louis Pasteur.

NELSON, R; WINTER, S. An evolutionary theory of economic change. Cambridge: Harvard University Press, 1982.

NONAKA, I.; TAKEUCHI, H. Criação do Conhecimento na Empresa. Rio de Janeiro: Campus, 1997. 358 p.

PRAHALAD, C.; HAMEL, G. The Core Competence of the Corporation. Harvard Business Review, v. 90, n. 3, p. 7990, 1990.

ROSENBERG, N. Inside the black-box. Cambridge: Cambridge University Press, 1982.

SENGE, P.M.A. A Quinta Disciplina: arte, teoria e prática da organização de aprendizagem. $7^{\mathrm{a}}$ ed. São Paulo: BestSeller, 1990.

STEWART, T. A. Capital intelectual. Rio de Janeiro: Campus, 1997. 
TEECE, D. Tecnological Change and the Nature of the Firm. In DOSI, G.; FREEMAN, C; NELSON, R; SILVERGERG, G.; SOETE, L. (eds.). Technical Change and Economic Theory. London: Printer, 1997.

TEECE, D.; PISANO, G; SHUEN, A. Dynamic Capabilities and Strategic Management. Strategic Management Journal, v. 18, n. 7, p. 509-533, 1997.

crossef

TEMPORÃO, J. G. Complexo Industrial da Saúde: público e privado na produção e consumo de vacinas no Brasil. 2002. 250 f. Tese (Doutorado em Saúde Coletiva) - Instituto de Medicina Social, Universidade do Estado do Rio de Janeiro.

Von HIPEL, E. The Sources of Innovation. Oxford University Press, New York, 1988.

\begin{abstract}
This article presents an evaluation of the organizational capabilities development necessary to innovate in an organization which developed basic technological capabilities through external technology acquisition and seeks to reach innovative characteristics. In view of capabilities in the organizations are accumulated in increasing levels of complexity from the basic one to the advanced one, it is evaluated the works perception related to the development level of these capabilities in the organization. The results indicate that despite the efforts in the acquisition of external technologies and knowledge in diverse manners, these are not yet expressed by the conversion of the individual knowledge in organizational knowledge. The perception of the people who work in the Institute is that the unrelated organizational capabilities to the acquisition, generation, socialization and codification of the knowledge still less developed than those ones.
\end{abstract}

Key-words: organization capabilities; organizational learning; innovative capabilities.

\title{
Dados dos Autores:
}

Nome completo: Antonio de Pádua Risolia Barbosa

Filiação Institucional: Fundação Oswaldo Cruz

Departamento: Instituto de Tecnologia em Imunobiológicos - Bio-Manguinhos

Função ou cargo ocupado: Tecnologista Sênior

Endereço completo para correspondência: Rua Senador Vergueiro 80, apto 602, Flamengo, Rio de

Janeiro, RJ, Brasil, CEP 22230001

Telefones para contato: $+55-21-3882-9330$

e-mail: barbosa@bio.fiocruz.br

Nome complete: Rosiceli Barreto Goncalves Baetas

Filiação Institucional: Fundaçao Oswaldo Cruz

Departamento: Vice-Presidencia de Produção e Inovação em Saúde

Função ou cargo ocupado: Analista em C\&T Senior

Endereço completo para correspondência: Rua Arquiteto Milton Roberto, 83 casa. Barra da Tijuca,

Rio de Janerio, RJ, Brasil. CEP 22641-120

Telefones para contato: $+55-21-3885-1798$ 
e-mail: rosiceli@,fiocruz.br

Nome complete: Jose Vitor Bomtempo Martins

Filiação Institucional: Universidade Federal do Rio de Janeiro

Departamento: Área Gestao e Inovação Tecnológica, Escola de Quimica; GEE Grupo de Economia da Energia, Instituto de Economia.

Função ou cargo ocupado: Professor

Endereço completo para correspondência: Rua Delfim Moreira, 199/400, Centro, Juiz de Fora, MG, Brasil, CEP 36010-570

Telefones para contato: $+55-21-3873-5269$

e-mail: vitor@eq.ufrj.br 